\title{
COMMENTARY
}

\section{Pulmonary and renal protection: targeting PARP to ventilator-induced lung and kidney injury?}

\author{
Martin Matejovic ${ }^{* 1}$ and Peter Radermacher ${ }^{2}$ \\ See related research by Vaschetto et al., http://ccforum.com/content/14/2/R45
}

\begin{abstract}
Both acute lung injury and acute kidney injury (AKI) are frequent and serious problems in intensive care medicine. Therefore, the avoiding of any iatrogenic insult to these organs is of great importance. While an increasing body of evidence suggests that mechanical ventilation is capable of inducing lung and distant organ injury, the complex underlying molecular mechanisms remain insufficiently understood. In the previous issue of Critical Care, Vaschetto and colleagues reported the results of an experimental study designed to further explore pathways linking injurious ventilation with AKI. The authors demonstrated that scavenging of peroxynitrite or inhibiting poly(ADP-ribose) polymerase (PARP) afforded protection against AKI induced by double-hit lung injury. Although PARP inhibition or peroxynitrite detoxification or both may become viable candidates for a protective strategy in this setting, the implementation of a lung-protective ventilatory strategy remains the only clinical tool to mitigate the lung biotrauma and its systemic consequences.
\end{abstract}

In the previous issue of Critical Care, Vaschetto and colleagues [1] sought to determine whether and by which mechanism(s) the activation of poly(ADP-ribose) polymerase (PARP) contributes to the acute kidney injury (AKI) induced by injurious mechanical ventilation (MV). The authors used a double-hit rat model of acute lung injury comprising lipopolysaccharide-induced lung inflammation and MV with either very high tidal volume $(19 \mathrm{~mL} /$ $\mathrm{kg}$, zero positive end-expiratory pressure [PEEP]) or low tidal volume $\left(6 \mathrm{~mL} / \mathrm{kg}\right.$, PEEP $\left.5 \mathrm{~cm} \mathrm{H}_{2} \mathrm{O}\right)$. To address the role of peroxynitrite and PARP in mediating MV-induced

\footnotetext{
${ }^{*}$ Correspondence: matejovic@fnplzen.cz

11st Medical Department, Charles University Medical School and Teaching

Hospital, alej Svobody 80, 30460 Plzen, Czech Republic

Full list of author information is available at the end of the article
}

kidney injury, the rats challenged with high-tidal-volume MV were pre-treated with peroxynitrite decomposition catalyst (WW85) or a PARP inhibitor (PJ-34). The authors' key findings were that both strategies preserved renal perfusion, attenuated renal endothelial dysfunction, and ameliorated intrarenal inflammation.

The issue of AKI due to MV is an old but still virtually not understood phenomenon and is, however, of major concern [2]. Traditionally, deteriorations in systemic and renal hemodynamics and gas exchange associated with MV have been implicated in this process [3]. There is an emerging concept that MV exerts a broad spectrum of harmful biological responses with the capacity to affect functions of remote organs $[4,5]$, including the kidney $[6,7]$. An altered inflammatory network, oxidative stress, and apoptosis have been considered the central hubs of this organ crosstalk in response to MV [8,9].

Generation of reactive oxygen and nitrogen species has been demonstrated during various acute conditions [10]. One of the most important secondary injuries resulting from oxidative stress is oxidative DNA damage leading to overactivation of PARP. Its activation results in depletion of $\mathrm{NAD}^{+}$and ATP and consequently in cell death and organ dysfunction [10]. Not only compromised cellular energy metabolism but also PARP-mediated upregulation of numerous pro-inflammatory pathways makes the pharmacological modulation of PARP activity a suitable target to prevent the tissue injury [10-12]. Therefore, the hypothesis of the peroxynitrite-PARP-dependent pathway as an important pathogenic contributor to ventilator-induced kidney injury [8] is tempting. Indeed, evidence derived from several studies suggests that PARP is activated in both ventilator-induced lung injury (VILI) [13] and AKI [14]. In addition to direct PARP inhibition, neutralization of cytotoxic effects of molecules such as iNOS (inducible nitric-oxide synthase)-derived nitric oxide might constitute an interesting tool to protect the kidney $[15,16]$.

The study by Vaschetto and colleagues [1] is a complementary experimental study of the research group that has previously demonstrated impressive beneficial effects of PARP inhibition on VILI, systemic inflammatory response, and kidney function in a very similar 
experimental setting [17]. Their present study [1] extends these findings by providing further insights into the mechanisms by which PARP inhibition provides kidney protection. Peroxinitrite-PARS (poly[ADP-ribose] synthetase) inhibition preserved renal microvascular stability and attenuated renal tissue leukocyte infiltration. These findings are of particular relevance to the kidney as recent research underscored the importance of renal microcirculation and intrarenal inflammation as possibly causative features in AKI $[18,19]$.

Although we have learned a great deal from the study by Vaschetto and colleagues [1], some critical aspects of the study need to be addressed. To induce significant VILI and remote organ dysfunction, the authors had to use highly injurious ventilatory settings associated with profound hypotension and this use would be considered non lege artis in clinical practice. Moreover, no standard therapeutic measures such as fluid resuscitation or vasoactive drugs to maintain renal blood flow were administered. Finally, they tested the role of the peroxynitrite-PARP-dependent pathway in animals challenged with high tidal volume only, thus leaving its role in clinically more relevant scenarios open to speculation. In fact, in their previous study, the authors observed no significant differences between animals ventilated with low tidal volume $(6 \mathrm{~mL} / \mathrm{kg}$, PEEP $5 \mathrm{~cm} \mathrm{H}_{2} \mathrm{O}$ ) and treated or not treated with PARP inhibition [17]. Therefore, it is tempting to speculate that lungprotective ventilation might produce only subtle inflammatory insults insufficient to trigger PARP overactivation in remote organs. Furthermore, the short-term nature and pre-treatment design of the study as well as the lack of direct measurements of time-related changes in tissue PARP activity and 3-nitrotyrosine (an index of peroxynitrite) make the applicability of the results to the clinical scenario problematic. Finally, the double-hit model does not allow investigators to dissect whether the major stimulus for peroxynitrite-PARP-derived toxicity is endotoxin or injurious ventilation or both.

Where do we go from here? Mitigation of VILI-induced lung and remote organ injury by interfering with the pathobiological pathways involved is a promising concept, albeit still far from the clinical arena. Though leaving important aspects open to speculation, the studies by Vaschetto and colleagues provide interesting mechanistic insights into the increasingly challenging aspects of the complex inflammatory network implicated in bidirectional organ crosstalk and should stimulate further research in this direction.

\section{Abbreviations}

AKl, acute kidney injury; MV, mechanical ventilation; PARP, poly(ADP-ribose) polymerase; PEEP, positive end-expiratory pressure; VILI, ventilator-induced lung injury.

\section{Competing interests}

The authors declare that they have no competing interests.

\section{Author details}

11st Medical Department, Charles University Medical School and Teaching Hospital, alej Svobody 80, 30460 Plzen, Czech Republic. ${ }^{2}$ Sektion Anästhesiologische Pathophysiologie und Verfahrensentwicklung, Universitätsklinikum, Parkstrasse 11, D-89075 Ulm, Germany.

\section{Acknowledgments}

This work was supported by research grant MSM 0021620819 ('Replacement of and support to some vital organs').

\section{Published: 6 May 2010}

\section{References}

1. Vaschetto R, Kuiper JW, Musters RJ, Eringa EC, Della Corte F, Murthy K, Groeneveld AJ, Plotz FB: Renal hypoperfusion and impaired endotheliumdependent vasodilation in an animal model of VILI: the role of the peroxynitrite-PARP pathway. Crit Care 2010, 14:R45.

2. Pannu N, Mehta RL: Mechanical ventilation and renal function: an area for concern? Am J Kidney Dis 2002, 39:616-624.

3. Kuiper JW, Groeneveld AB, Slutsky AS, Plötz FB: Mechanical ventilation and acute renal failure. Crit Care Med 2005, 33:1408-1415.

4. Slutsky AS, Tremblay LN: Multiple system organ failure. Is mechanical ventilation a contributing factor? Am J Respir Crit Care Med 1998, 157:1721-1725.

5. Plotz FB, Slutsky AS, van Vught AJ, Heijnen CJ: Ventilator-induced lung injury and multiple system organ failure: a critical review of facts and hypotheses. Intensive Care Med 2004, 30:1865-1872.

6. Imai Y, Parodo J, Kajikawa O, de PM, Fischer S, Edwards V, Cutz E, Liu M, Keshavjee S, Martin TR, Marshall JC, Ranieri VM, Slutsky AS: Injurious mechanical ventilation and end-organ epithelial cell apoptosis and organ dysfunction in an experimental model of acute respiratory distress syndrome. JAMA 2003, 289:2104-2112.

7. Douillet CD, Robinson WP 3rd, Zarzaur BL, Lazarowski ER, Boucher RC, Rich PB: Mechanical ventilation alters airway nucleotides and purinoceptors in lung and extrapulmonary organs. Am J Respir Cell Mol Biol 2005, 32:52-58.

8. Koyner JL, Murray PT: Mechanical ventilation and the kidney. Blood Purif 2010, 29:52-68

9. Ricci Z, Ronco C: Pulmonary/renal interaction. Curr Opin Crit Care 2010, 16:13-18

10. Barth E, Radermacher P, Szabó C: The world according to poly(ADP-ribose) polymerase (PARP)--update 2006. Intensive Care Med 2006, 32:1470-1474.

11. Maier C, Scheuerle A, Hauser B, Schelzig H, Szabó C, Radermacher P, Kick J: The selective poly(ADP)ribose-polymerase 1 inhibitor INO1001 reduces spinal cord injury during porcine aortic cross-clamping-induced ischemia/ reperfusion injury. Intensive Care Med 2007, 33:845-850.

12. Gerö D, Szabó C: Poly(ADP-ribose) polymerase: a new therapeutic target? Curr Opin Anaesthesiol 2008, 21:111-121.

13. Kim JH, Suk MH, Yoon DW, Kim HY, Jung KH, Kang EH, Lee SY, Lee SY, Suh IB, Shin C, Shim JJ, In KH, Yoo SH, Kang KH: Inflammatory and transcriptional roles of poly (ADP-ribose) polymerase in ventilator-induced lung injury. Crit Care 2008, 12:R108.

14. Devalaraja-Narashimha K, Singaravelu K, Padanilam BJ: Poly(ADP-ribose) polymerase-mediated cell injury in acute renal failure. Pharmacol Res 2005 52:44-59.

15. Heemskerk S, Masereeuw R, Russel FG, Pickkers P: Selective iNOS inhibition for the treatment of sepsis-induced acute kidney injury. Nat Rev Nephrol 2009, 5:629-640

16. Matejovic M, Krouzecky A, Martinkova V, Rokyta R Jr., Kralova H, Treska V, Radermacher $P$, Novak I: Selective inducible nitric oxide synthase inhibition during long-term hyperdynamic porcine bacteremia. Shock 2004, 21:458-465.

17. Vaschetto R, Kuiper JW, Chiang SR, Haitsma JJ, Juco JW, Uhlig S, Plotz FB, Corte FD, Zhang H, Slutsky AS: Inhibition of poly(adenosine diphosphateribose) polymerase attenuates ventilator-induced lung injury. Anesthesiology 2008, 108:261-268.

18. Le Dorze M, Legrand M, Payen $D$, Ince $C$ : The role of the microcirculation in acute kidney injury. Curr Opin Crit Care 2009, 15:503-508.

19. Jang HR, Rabb H: The innnate immune response in ischemic acute kidney injury. Clin Immunol 2009, 130:41-50.

\section{doi:10.1186/cc8982}

Cite this article as: Matejovic M, Radermacher P: Pulmonary and renal protection: targeting PARP to ventilator-induced lung and kidney injury? Critical Care 2010, 14:147. 